\title{
VARIAÇÃO MORFOMÉTRICA E DEMOGRÁFICA EM PHALERIA TESTACEA SAY (COLEOPTERA, TENEBRIONIDAE) DE DUAS PRAIAS DO RIO DE JANEIRO
}

\author{
M.D. de Almeida ${ }^{1}$ \\ A. Caldas ${ }^{2}$ \\ J.R. de Almeida ${ }^{3}$
}

\begin{abstract}
MORPHOMETRY AND ABUNDANCE OF PHALERIA TESTACEA SAY (COLEOPTERA, TENEBRIONIDAE) FROM TWO BEACHES OF RIO DE JANEIRO. The species Phaleria testacea Say, 1824 (Coleoptera, Tenebrionidae) varies a lot in size, and its populations along the coast of Brazil, where it lives buried in sandy beaches, have temporal and geographical variation in density. In order to find out which factors were contributing to these variations, we sampled populations from three different areas in Rio de Janeiro, during summer and winter. Simultaneously, we made an analysis of the different substracts where the individuals were found, including their total fresh weight. The results show a significant difference in size of individuals between and within populations, when summer and winter were compared. There is also a positive association between the population density of P. testacea and the amount of "garbage" found at the study areas.

KEY WORDS. Coleoptera, Tenebrionidac, Phaleria testacea, morphometry, abundance
\end{abstract}

Sabe-se que as espécies animais têm sua estrutura fenotípica definida em função de interaçôes do genótipo com o ambiente. A Genética Ecológica apresenta diversas teorias neste sentido (FORD, 1975). Em insetos, é comum a variabilidade fenotípica tanto em tamanho como em cor dentro da mesma espécie, dependendo do tipo de ambiente a que são submetidos os indivíduos (MAYR, 1977). Dentro deste contexto, temperatura e umidade surgem como fatores altamente importantes em estudos de populações de insetos (MALTAIS et al., 1980; KING et al., 1981).

Phaleria testacea Say, 1824 (Coleoptera, Tenebrionidae) é uma espécie que habita praias arenosas em quase todo o litoral oriental das Américas (WATROUS \& TRIPLEHORN, 1982); vive enterrado na areia durante o dia, subindo à superfície à noite e alimentando-se de todo tipo de detrito existente

1) Departamento de Entomologia, Fundação Instituto Oswaldo Cruz, Caixa Postal 926, 21041-210 Rio de janeiro, Rio de Janeiro, Brasil.

2) Setor de Ecologia, Universidade Estadual do Rio de Janeiro, Rua São Francisco Xavier, 524, 20050-013 Rio de Janeiro, Rio de Janeiro, Brasil.

3) Departamento de Ecologia, Universidade Federal do Rio de Janeiro, Caixa Postal 68020, 21944-970 Rio de Janeiro, Rio de Janeiro, Brasil. 
na praia (CALDAS \& ALMEIDA, 1985). Através de estudos desenvolvidos desde 1979 com esta espécie, foi observado que havia uma grande variabilidade em tamanho dos indivíduos, fato já observado por TRIPLEHORN \& WATROUS (1979). Aparentemente, também havia maior densidade destes insetos em praias com maior quantidade de detritos na areia ou seja, maior oferta de alimento mas até o momento nada ainda havia sido quantificado.

Segundo THORPE (1976) a morfometria pode testar variação geográfica e racial. A morfometria, definida como a caracterização de formas biologicamente relevantes, permite a utilização quantitativa de resultados em Biologia Evolutiva. No que tange à confiabilidade, as medidas podem ter seu poder descritivo aumento quando feitas em grande quantidade, porém muitas vezes um número pequeno de medidas oferece tão bons resultados quanto um número grande (OXNARD, 1978), desde que haja a comparação de muitos exemplares diferentes.

Este trabalho foi realizado com os seguintes objetivos: 1) Identificar se há realmente associação entre o número de indivíduos e a quantidade de "lixo" na praia; caso isto se confirme, a espécie poderá ser um indicador ecológico de poluição do substrato arenoso; 2) Verificar se há variabilidade morfométrica significativa em $P$. testacea entre populações e dentro de uma mesma população em diferentes épocas (variação sazonal), a partir de análises de amostras de estações mais frias e secas e estações mais quentes e úmidas (definidas como inverno e verão, respectivamente). Caso esta hipótese se confirme, será talvez um passo para explicar a grande variabilidade ao longo de toda sua distribuição geográfica.

\section{MATERIAL E MÉTODOS}

\section{ÁREA DE ESTUDOS}

O estudo foi desenvolvido em duas praias do estado do Rio de Janeiro: Botafogo (localização aproximada $22^{\circ} 56^{\prime} \mathrm{S} / 43^{\circ} 10^{\prime} \mathrm{W}$ ) e Piratininga (localização aproximada $22^{\circ} 57^{\prime} \mathrm{S} / 43^{\circ} 03^{\prime} \mathrm{W}$ ). Ambas apresentam diferentes níveis de poluição do substrato arenoso, devido à frequência diferenciada de banhistas. Além disso, Botafogo é praia interna à Baía de Guanabara, com pouca circulação de água e Piratininga é de mar aberto, circulação maior de água e modo mais batido. Esta última foi dividida em duas áreas, I e II, com diferentes quantidades de detritos porém submetidas às mesmas condiçōes climáticas.

\section{METODOLOGIA}

As coletas foram feitas em janeiro e julho/86 (verão e inverno respectivamente) nas três áreas. Dentro das áreas de estudo em cada praia, divididas em 100 parcelas de amostragem num total de $100 \mathrm{~m}^{2}$, eram sorteadas 10 , e dentro destas efetuava-se uma coleta exaustiva dos indivíduos. Conservados em álcool a $70 \%$, estes eram posteriormente contados e medidos com paquímetro de precisão. Para morfometria foram utilizados o comprimento total e a largura do pronoto próximo à linha de inserção dos élitros. O teste t de Student foi utilizado 
para verificar a igualdade das médias dos dados morfométricos dos espécimens das três áreas de coleta.

Todos os detritos encontrados dentro das parcelas sorteadas eram descritos e pesados. Posteriormente, estes detritos foram agrupados em quatro classes (Tab. I) e foi utilizado o teste do Qui-Quadrado para verificar a associação da quantidade de "lixo" com a densidade de $P$. testacea nas três áreas de coleta.

Tabela 1. Classes de detritos nas praias de Botafogo e Piratininga (numerador=número encontrado; denominador $=$ número total existente nas duas praias) e peso total por área de estudo.

\begin{tabular}{lcccccccc}
\hline & \multicolumn{2}{c}{ Botafogo } & & \multicolumn{2}{c}{ Piratininga I } & & \multicolumn{2}{c}{ Piratininga II } \\
\cline { 2 - 3 } \cline { 7 - 8 } \cline { 7 - 8 } & Verão & Inverno & & Verão & Inverno & & Verão & Inverno \\
\hline Vegetal & $9 / 14$ & $7 / 14$ & & $9 / 14$ & $7 / 14$ & & $6 / 14$ & $4 / 14$ \\
Animal & $3 / 7$ & $1 / 7$ & & $3 / 7$ & $3 / 7$ & & $4 / 7$ & $3 / 7$ \\
Manufaturados & $18 / 31$ & $11 / 31$ & & $21 / 31$ & $11 / 31$ & & $11 / 31$ & $9 / 31$ \\
Outros & $4 / 4$ & $1 / 4$ & & $2 / 4$ & $2 / 4$ & & $2 / 4$ & $1 / 4$ \\
Peso Total (g) & 295,25 & 340,50 & & 728,86 & 1139,81 & & 481,12 & 662,60 \\
\hline
\end{tabular}

\section{RESULTADOS E DISCUSSÃO}

Foram encontrados 55 tipos de detritos, agrupados em quatro classes (Tab. I). na classe "outros" incluem-se aqueles cuja origem não foi possível identificar. Nem todos foram encontrados nas três áreas, e o número encontrado em relação ao total absoluto por classe encontra-se na tabela I, assim como o peso total de detritos por área amostrada.

Os valores de média e variância para as medidas utilizadas estão na tabela 2. O teste $\mathbf{t}$ para estas medidas foi significante na maioria dos casos (Tab. III), assim como o teste do Qui-Quadrado para associação de frequência de detritos e indivíduos (Tab. IV).

As variaçōes observadas entre indivíduos de verão e inverno numa mesma praia podem ser atribuídas a diferentes níveis de associação de temperatura e umidade relativa. Ao longo do litoral brasileiro, já foi observada a influência positiva de menor temperatura e maior precipitaçāo (com consequente menor evaporação) no desenvolvimento de $P$. testacea, uma vez que os indivíduos mais ao sul tendem a ser maiores. Nas praias observadas neste trabalho, os indivíduos maiores são sempre encontrados no verão (Tab. II), quando há maior precipitação, porém altas temperaturas. Isto sugere a influência maior da precipitação no desenvolvimento de $P$. testacea (maior precipitação, maior tamanho, independentemente da temperatura).

Já a densidade de $P$. testacea no litoral brasileiro é maior quanto mais para o sul é a praia, o que significa menor temperatura e maior precipitação média. Nas três áreas aqui consideradas as maiores densidades estão associadas ao inverno, que tem menor temperatura mas também menor precipitação. 
Tabela 2. Valores de média e variância para as medidas utilizadas na análise morfométrica de $\mathbf{P}$. testacea no Rio de Janeiro.

\begin{tabular}{|c|c|c|c|c|c|c|}
\hline Praia & Estação & $\begin{array}{c}\text { Total } \\
\text { coletado }\end{array}$ & $\begin{array}{c}\text { Largura } \\
\text { média }\end{array}$ & $\begin{array}{l}\text { Pronoto } \\
(\mathbf{m m}) \text { Var. }\end{array}$ & $\begin{array}{l}\text { Comprimento } \\
\text { média }\end{array}$ & $\begin{array}{c}\text { Total (mm) } \\
\text { Var. }\end{array}$ \\
\hline \multirow{3}{*}{ Botafogo } & Verão & 401 & 2,39 & 0,03 & 7,13 & 0,27 \\
\hline & & & & & & \\
\hline & Inverno & 493 & 2,36 & 0,02 & 7,03 & 0,25 \\
\hline \multirow{3}{*}{ Piratininga I } & Verão & 265 & 2,57 & 0,02 & 7,50 & 0,41 \\
\hline & & & & & & \\
\hline & Inverno & 325 & 2,47 & 0,02 & 7,21 & 0,31 \\
\hline \multirow{3}{*}{ Piratininga II } & Verão & 145 & 2,57 & 0,02 & 7,61 & 0,41 \\
\hline & & & & & & \\
\hline & Inverno & 355 & 2,50 & 0,02 & 7,37 & 0,38 \\
\hline
\end{tabular}

Tabela 3. Valores do teste $\mathbf{t}$ para as medidas utilizadas na análise morfométrica de P. testacea no Rio de Janeiro.

\begin{tabular}{|c|c|c|c|c|c|c|c|}
\hline \multirow{2}{*}{\multicolumn{2}{|c|}{$\begin{array}{l}\text { Comprimento total } \\
\text { Pronoto largura }\end{array}$}} & \multicolumn{2}{|c|}{ Botafogo } & \multicolumn{2}{|c|}{ Piratininga I } & \multicolumn{2}{|c|}{ Piratininga II } \\
\hline & & Verão & Inverno & Verāo & Inverno & Veräo & Inverno \\
\hline & Verão & 0,00 & $2,90^{* *}$ & $7,85^{* *}$ & $1,98^{*}$ & $8,10^{* *}$ & $5,74^{* *}$ \\
\hline \multicolumn{8}{|l|}{ Botafogo } \\
\hline & Inverno & $2,80^{* *}$ & 0,00 & $10,37^{* *}$ & $4,71^{* *}$ & $10,05^{* *}$ & $8,56^{* *}$ \\
\hline & Verão & $11,63^{* *}$ & $19,44^{* *}$ & 0,00 & $5,80^{* *}$ & $2,16^{*}$ & $2,53^{* *}$ \\
\hline \multicolumn{8}{|l|}{ Piratininga I } \\
\hline & Inverno & $6,83^{* *}$ & $10,89^{* *}$ & $8,54^{* *}$ & 0,00 & $6,50^{* *}$ & $3,55^{* *}$ \\
\hline & Verão & $12,32 * *$ & $15,67^{* *}$ & 0,00 & $7,09^{* *}$ & 0,00 & $3,84^{* *}$ \\
\hline \multicolumn{8}{|l|}{ Piratininga II } \\
\hline & Inverno & $9,56^{* *}$ & $14,28 * *$ & $6,08^{* *}$ & $2,75^{* *}$ & $5,03^{* *}$ & 0,00 \\
\hline
\end{tabular}

* Significativo ao nível de 0,05 de probabilidade.

** Significativo ao nível de 0,01 de probabilidade.

Regressões feitas para amostras populacionais na praia de Botafogo durante dois anos (CALDAS, não publicado) indicam tendência do número de indivíduos diminuir com o aumento da temperatura (isto tudo independentemente do nível de detritos existentes).

Já foi observado que populaçōes de insetos tropicais podem ter comportamento cíclico semelhante aos insetos de região temperada, independente da existência de várias gerações. Segundo WOLDA (1988) aparentemente os insetos tropicais podem flutuar amplamente em abundância, e quanto maior a 
imprevisibilidade pluviométrica maior seria esta flutuação; pois na região tropical pode haver uma maior homogeneidade em termos de temperatura, mas a chuva é muito variável. Não se sabe há oscilações dependentes da densidade no caso de $P$. testacea, porém parece haver uma escala de tempo controlada por algum fator ambiental (talvez a temperatura, que segundo KITCHING 1977 é o mais comum) que influencie a população independentemente de sua densidade.

Tabela 4. Valores do Qui-Quadrado para as freqüências de "lixo" e densidade de P. testacea em praias do Rio de Janeiro (verão e inverno).

\begin{tabular}{lcc}
\hline \multirow{2}{*}{ Praia } & \multicolumn{2}{c}{ Valor do $\mathbf{X}^{2}$} \\
\cline { 2 - 3 } & Lixo & Densidade \\
\hline Botafogo & 3,22 & $9,46^{*}$ \\
Piratininga I & $90,25^{*}$ & $6,10^{*}$ \\
Piratininga II & $28,79^{*}$ & 88,20 \\
\hline
\end{tabular}

* Significativo ao nível de 0,05 de probabilidade.

As condições ambientais foram sempre associadas com o tipo de seleção (ver MAYR, 1977). Assim, climas tropicais (mais homogêneos) levariam a habitats relativamente estáveis, com uma amplitude de variação pequena (uma vez que o clima não é o único interferente). Como a estabilidade de um habitat para determinado animal depende da relação entre o tempo geracional e o intervalo de tempo em que o habitat permanece favorável (SOUTHWOOD et al., 1974), e considerando que $P$. testacea tem ciclo de vida longo e o habitat está constantemente favorável (pelo fato de a população deslocar-se constantemente em busca de uma faixa "ótima") acreditamos que a variação de tamanho observada não seja nenhum tipo de resultado de seleção direcional ( $c f$. PIANKA, 1983) de acordo com a época do ano, mas uma simples consequência fisiológica resultante das condições ambientais, ou seja, em determinadas condições os indivíduos em desenvolvimento apresentariam maior ou menor tamanho, e não apenas os maiores ou menores seriam selecionados no habitat. Resta identificar em que estágio do jovem se dá esta definição no tamanho e que fatores determinariam tal característica. Cabe ressaltar que tanto machos como fêmeas têm redução proporcionalmente similar (pois os machos são em geral menores que as fêmeas) assim como tal redução também independe do padrão de pigmentação do indivíduo. A população como um todo é contingenciada. É de se frisar também que todas as diferenças de medidas são significantes, exceto no verão entre as duas áreas de coleta em Piratininga (Tab. III).

No que tange à associação entre densidade e quantidade de detritos, acreditamos ser uma simples consequência da maior oferta de recursos alimentares. Porém, só com análises mais detalhadas, a partir de outras amostras, de outros locais, e de experimentos controlados, poderemos afirmar algo. 
AGRADECIMENTOS. Ao Sr. Luiz de Almeida pela incansável ajuda nas coletas e pelo grande apoio dado à realização deste trabalho.

\section{REFERÊNCIAS BIBLIOGRÁFICAS}

CALDAS, A. \& ALMEIDA, J.R. 1985. Hábitos alimentares e comportamento de Phaleria brasiliensis Laporte, 1840 (Coleoptera, Tenebrionidae) na praia de Botafogo, Rio de Janeiro, RJ. Revta bras. Ent. 29 (2): 221-224.

FORD, E.B. 1975. Ecological genetics. London, Chapman \& Hall, 442p.

KING, P.D.; C.F. MERCER \& J.S. MEEKINGS. 1981. Ecology of the black beetle Heteronychus arator (Coleoptera, Scarabeidae). Influence of temperature on feeding, growth, and survival of the larvae. New Zeal. J. Zool. 8: 113-117.

KITCHING, R.L. 1977. Time, resources and population dynamics in insects. Austr. J. Ecol. 2: 31-42.

MALTAIS, P.M.; J.J. JUILLET \& D.D. OLIVEIRA. 1980. Écologie et dynamique des populations de la tenthrède du mélèze, Pristiphora Erichsonii (Htg), au parc national de Kouchibouguac au Nouveau-Brunswick. Ann. Soc. Ent. Québec. 25: 141-162.

MAYR, E. 1977. Populaçōes, espécies e evolução. São Paulo, Ed. Nacional e EDUSP, 485p.

OXNARD, C.E. 1978. One biologist's view of morphometrics. Rev. Ecol. Syst. 9: 219-241.

PIANKA, E.R. 1983. Evolutionary ecology. New York, Harper \& Row, 416p.

SOUTHWOOD, T.R.E.; R.M. MAY \& M.P. HASSEL. 1974. Ecological strategies and population parameters. Am. Nat. 108 (964): 791-804.

THORPE, R.S. 1976. Biometric analysis of geographical variation and racial affinities. Biol. Rev. 51: 407-452.

TRIPLEHORN, C.A. \& L.E. WATROUS. 1979. A synopsis of the genus Phaleria in the United States and Baja California (Coleoptera: Tenebrionidae). The Col. Bull. 33 (3): 275-295.

WATROUS, L.E. \& C.A. TRIPLEHORN. 1982. Phaleria of the West Indies and circum-Caribbean region (Coleoptera: Tenebrionidae). The Col. Bull. 36 (1): 12-21.

WOLDA, H. 1988. Insect seasonality: why? Ann. Rev. Ecol. Syst. 19: 1-18.

Recebido em 20.IX.1993; aceito em 25.XI.1993. 